\title{
Adsorption and Bioadsorption of Granular Activated Carbon (GAC) for Dissolved Organic Carbon (DOC) Removal in Wastewater
}

\author{
W. Xing, H. H. Ngo ${ }^{*}$, S. H. Kim, W. S. Guo and P. Hagare \\ University of Technology, Sydney, PO Box 123, Broadway, NSW 2007, Australia \\ * Corresponding author (Tel: 61-2-95141693, Fax: 61-2-95142633, Email: h.ngo@uts.edu.au)
}

\begin{abstract}
In this study, the performances of GAC adsorption and GAC bioadsorption in terms of dissolved organic carbon (DOC) removal were investigated with synthetic biologically treated sewage effluent (BTSE), synthetic primary treated sewage effluent (PTSE), real BTSE and real PTSE. The main aims of this study are to verify and compare the efficiency of DOC removal by GAC (adsorption) and acclimatized GAC (bioadsorption). The results indicated that the performance of bioadsorption was significantly better than that of adsorption in all cases, showing the practical use of biological granular activated carbon (BGAC) in filtration process. The most significance was observed at a real PTSE with a GAC dose of $5 \mathrm{~g} / \mathrm{L}$, having $54 \%$ and $96 \%$ of DOC removal by adsorption and bioadsorption, respectively. In addition, it was found that GAC adsorption equilibrium was successfully predicted by a hybrid Langmuir - Freundlich model whilst integrated linear driving force approximation (LDFA) + hybrid isotherm model could describe well the adsorption kinetics. Both adsorption isotherm and kinetic coefficients determined by these models will be useful to model the adsorption/bioadsorption process in DOC removal of BGAC filtration system.
\end{abstract}


Keywords: GAC adsorption; GAC bioadsorption; adsorption modeling; dissolved organic carbon; wastewater

\section{Introduction}

The domestic wastewater typically contains pathogens, suspended solids, nutrients (nitrogen and phosphorus) and other organic pollutants. For curtailing the environmental and health hazards, these pollutants need to be removed to permissible limits for safe disposal of wastewater (Devi and Dahiya, 2008). Consequently, removal of the organic contaminants and pathogens from wastewater is very important for its reuse in different activities.

Activated carbon adsorption has been widely applied in removing organic matters from wastewater as it has a strong affinity for attaching organic substances even at low concentration. Having large surface area for adsorption, granular activated carbon (GAC) is one of the best adsorbents for removing various organic contaminants (Nishijima et al, 1997). The GAC adsorption systems are therefore considered to apply for producing the effluent of high quality from sewage treatment plant which can be reused for various purposes. However, even though it has high adsorption capacity, GAC can only maintain its adsorption for a short time after its available adsorption site becomes exhausted with adsorbed organic pollutants (Aktas and Cecen, 2007). It is well known that GAC is also a good support media for microbial growth. Thus, 
biological GAC (BGAC) with attached biomass can effectively remove organic contaminants both by adsorption and biodegradation (Nishijima et al, 1997; Carvalho et al, 2007). The concept of bioadsorption is that adsorption is more dominant before GAC is in full adsorption capacity and the biodegradation play major role after that (Hoang, 2005; Aktas and Cecen, 2007). The GAC bioadsorption is usually applied in the bioreactors either fixed bed or fluidized bed configurations (Aktas and Cecen, 2007). The previous studies showed that GAC bioadsorption systems were very efficient (Zhao et al., 1999; Maloney et al, 2002; Loh and Ranganath, 2005; Persson et al., 2005; Hoa et al., 2008) due to their simultaneous adsorption of non-biodegradable matter and oxidation of biodegradable contaminants in a single reactor.

The main objectives of this study are: (i) to compare the adsorption and bioadsorption capacity of GAC in terms of dissolved organic carbon (DOC) removal from different wastewaters; and (ii) to develop the suitable adsorption isotherm and kinetic models which can be used for a column model to predict DOC removal in the BGAC filtration system.

\section{Experimental}

\subsection{Materials}

\subsubsection{Wastewaters used}

A. Synthetic wastewaters

1. Primary treated sewage effluent (PTSE) 
The compositions of synthetic wastewater used in this study are presented in Table 1 . It represents the wastewater after primary treatment. The average DOC concentration of this synthetic PTSE is around $120 \mathrm{mg} / \mathrm{L}$.

2. Biologically treated sewage effluent (BTSE)

Table 1 also shows the composition of BTSE used in this study. It is the representative of the effluent from biological treatment. The average DOC concentration of synthetic BTSE is about $10 \mathrm{mg} / \mathrm{L}$.

Table 1 Composition of synthetic BTSE and PTSE

B. Real wastewaters

1. Real PTSE

The sewage was collected from the SOPA (Sydney Olympic Park Authority) Wastewater Treatment Plant. The average DOC of real PTSE is around 55mg/L.

\section{Real BTSE}

The real BTSE was also derived from the SOPA Wastewater Treatment Plant. It is the effluent from the sequencing batch bioreactor (SBR) process and the DOC is around $10 \mathrm{mg} / \mathrm{L}$.

\subsubsection{GAC used}

The coal based GAC (ACTICARB GS1300, Activated Carbon Technologies Pty Ltd, Australia) was used in this study. This coal based GAC has a surface area of $>1100$ $\mathrm{BET} \mathrm{m}^{2} / \mathrm{g}$, an iodine number of $>1100 \mathrm{mg} /$ (g.min) and maximum ash and moisture 
contents of $10 \%$ and $3 \%$ respectively. Prior to use in experiments, the GAC was rinsed with distilled water to remove fines and dried at $105^{\circ} \mathrm{C}$ in the oven.

\subsection{Experiments}

\subsubsection{GAC adsorption isotherm and kinetics}

Equilibrium adsorption experiments were conducted at room temperature $\left(25^{\circ} \mathrm{C}\right)$ with synthetic BTSE, synthetic PTSE, real BTSE and real PTSE, respectively. Sodium hydrogen chloride $(\mathrm{NaOCl})$ was added into wastewater to prevent microorganism growth. Different doses of GAC were distributed into $250 \mathrm{ml}$ flask containing $100 \mathrm{ml}$ wastewater. To avoid the influence of the light, all flasks were covered by aluminum foil. All samples were shaken continuously for 90 hours on a shaking table at speed $130 \mathrm{rpm}$. After 90 hours shaking, samples of wastewater were taken from all flasks and filtered through $0.45 \mu \mathrm{m}$ filter prior to DOC analysis. The adsorbed amount (q) from equilibrium experimental data was calculated by the following equation:

$q=\frac{V\left(C_{i}-C_{e}\right)}{M}$

Where $q$ is the adsorbed amount $(\mathrm{mg} / \mathrm{g}), V$ is the volume $(\mathrm{L})$ of solution, $C_{i}$ is the initial DOC concentration of wastewater $(\mathrm{mg} / \mathrm{L}), C_{e}$ is the equilibrium DOC concentration $(\mathrm{mg} / \mathrm{L}), M$ is the amount of adsorbents $(\mathrm{g})$

In the experiment of kinetics adsorption, GAC was distributed into 2 liters beaker filled with wastewater at three different concentrations. The solutions with GAC were mixed using mechanical stirrer at speed of $110 \mathrm{rpm}$ for 6 hours and 72hours, respectively. 
During the kinetic experiment, samples were taken from these three beakers at different period of time and filtered through $0.45 \mu \mathrm{m}$ filter before analyzing DOC. The performance of GAC adsorption was evaluated in terms of DOC removal efficiency $(\%)$, which is estimated by the following equation:

$R E=\frac{\left(C_{i} \quad C_{t}\right)}{C_{i}} \times 100$

Where $C_{i}$ and $\mathrm{C}_{\mathrm{t}}$ are the initial and equilibrium DOC concentration.

\subsubsection{BGAC experiments}

For the comparison study, same procedure as in GAC adsorption isotherm experiments was adopted for BGAC experiments. Fresh GAC was acclimatized to the synthetic wastewater in a $10 \mathrm{~L}$ aeration tank. Certain volume of GAC was taken from tank to measure the biomass. As soon as the biomass attached on GAC reaches the steady phase, these acclimatized GAC will be used in the BGAC experiments.

\subsection{Analysis}

DOC concentration of water sample was measured using Analytikjena Multi N/C 2000 analyzer. The biomass (monitored as mixed liquor volatile suspended solid, MLVSS) was measured by APHA Standard Method (1998). For measuring MLVSS, two samples were taken each time and calculated the average. YSI 5300 Biological Oxygen Monitor was used to measure the specific oxygen uptake rate (SOUR).

\section{Theoretical approach}

\subsection{Adsorption isotherm}


Adsorption isotherm is basic requirement for designing any adsorption system. Isotherm express the relation between the amounts of adsorbate removed from liquid phase by unit of mass of adsorbent at fixed temperature. Since adsorption is one of the fundamental surface phenomena, it is important to have a satisfactory description of an equilibrium state in order to successfully represent the kinetic adsorption behavior of any species from the fluid to the solid phase.

An accurate mathematical description of equilibrium adsorption capacity is indispensable for reliable prediction of adsorption parameters and quantitative comparison of adsorption behavior for different adsorbent system. These parameters of equilibrium isotherm often provide some insight into sorption mechanism, surface properties and affinity of the adsorbent (Passos et al., 2008).

In general, the three or more -parameter models fitted the experimental data better than the two-parameter models. Thus, a four-parameter hybrid Langmuir-Freundlich isotherm model was employed to describe the adsorption equilibrium in this study. This hybrid isotherm model is based on Langmuir and Freundlich equations. It is expressed by Equation 3:

$q=\frac{q_{m} \cdot b \cdot C}{1+b \cdot C}+k \cdot C^{1 / n}$

Where, $\mathrm{q}$ is the adsorbed amount $(\mathrm{mg} / \mathrm{g}), \mathrm{C}$ is the equilibrium organic concentration $(\mathrm{mg} / \mathrm{L}), \mathrm{q}_{\mathrm{m}}, \mathrm{b}, \mathrm{k}$ and $\mathrm{n}$ are hybrid Langmuir-Freundlich constants.

At low sorbate concentration, it effectively reduces to a Freundlich isotherm and thus do not obey Henry's Law. At high adsorbate concentrations, it predicts the monolayer 
sorpotion capacity characteristics of the Langmuir isotherm (Cooney, 1998).

\subsection{Adsorption kinetic}

Adsorption kinetics study is important in treatment of aqueous effluents as it provides valuable information on the reaction pathway and in the mechanism of adsorption reactions. The adsorption kinetics was described by Linear driving force approximation (LDFA) model with total batch mass balance. It was selected because of its simplicity and use of DOC concentration to represent the liquid phase concentration of the system (Lee et al., 1997). The material balance in the batch reactor can be described by (Gordon, 1996; Bansal and Goyal, 2005)

$$
\frac{d C}{d t}=-\frac{M}{V} \frac{d q}{d t}
$$

The mass transfer rate between liquid and solid phase represented by LDFA model (Equation 5):

$$
\frac{d q}{d t}=\frac{3 \times k_{f}}{R \times \rho_{p}}\left(c_{i}-c_{s}\right)
$$

Where $R$ is radius of adsorbent $(\mathrm{m}), k_{f}$ is overall mass transfer coefficient $(\mathrm{m} / \mathrm{s}), \rho_{p}$ is density of particle $\left(\mathrm{kg} / \mathrm{m}^{3}\right), c_{i}$ is initial concentration of adsorbate in fluid phase $(\mathrm{mg} / \mathrm{L})$, $c_{s}$ is concentration of adsorbate in fluid phase at equilibrium $(\mathrm{mg} / \mathrm{L})$.

It is assumed that the adsorption rate of adsorbate by GAC is linearly proportional to a driving force using the LDFA model, defined as the difference between the surface concentration and the average adsorbed-phase concentration. The value of $\mathrm{k}_{\mathrm{f}}$ can be computed using the isotherm parameters in Equations 4 and 5. It could be applied to 
predict the kinetic experimental data. Regardless of the amount of the adsorbents, kinetic constants had the same value with same concentration and temperature (Lee et al., 2007).

\section{Results and discussion}

\subsection{Performance of GAC adsorption}

The adsorption isotherms of GAC in four different kinds of wastewaters are shown in Table 2. The results indicate that the DOC removal efficiencies enhanced with increasing in GAC dosage whilst decreasing in the equilibrium adsorbed amount. For example, varying the dosage of GAC from $0.25 \mathrm{~g} / \mathrm{l}$ to $5 \mathrm{~g} / \mathrm{L}$ increased the DOC removal efficiencies from $40 \%$ to $93 \%$. However, the amount of organic matter adsorbed on GAC dropped from $13.88 \mathrm{mg} / \mathrm{g}$ to $1.58 \mathrm{mg} / \mathrm{g}$ from synthetic BTSE. The similar results could also be seen from the experiments of equilibrium adsorption with other wastewaters. This could be explained that as at higher GAC dosage, the ratio of the initial concentration of organic matters to the GAC available site is low and subsequently the fraction of sorption is independent of the initial concentration. On the other hand, at the lower GAC dosage, the available sites became fewer compared to the amount of organic matter and hence resulted in the lower DOC removal efficiency. The results also found that the optimum doses of the GAC in removing organic matter from synthetic BTSE, synthetic PTSE, real BTSE and real PTSE were 5g/L, 50g/L, 1g/L and $40 \mathrm{~g} / \mathrm{L}$, which resulted in approximately 93\%, 84\%, 99\% and 83\% DOC removal efficiency, respectively.

Table 2 Performance of GAC adsorption 
Description of adsorption equilibrium by an appropriate isotherm is the most important step to design an adsorption system as it reflects the capacity or affinity of an adsorbent for a particular adsorbate. In this study, a hybrid Langmuir-Freundlich isotherm model was found to fit well with GAC equilibrium results. The values of hybrid Langmuir -Freundlich isotherm constants, $\mathrm{q}_{\mathrm{m}}, \mathrm{b}, \mathrm{k}, \mathrm{n}$ estimated from the plots along with the coefficients are listed in Table 3. The $\mathrm{q}_{\mathrm{m}}$ is attributable to the saturation amount of organic matters adsorbed. Relative low intensities of adsorption were displayed with four kinds of wastewaters, which correspond to low degrees of favourability of adsorption $(\mathrm{n}<1)$. The model results indicated that the GAC adsorption was successfully predicted by hybrid Langmuir-Freundlich model $\left(\mathrm{R}^{2}>0.9\right)$. Hence, the combined model was able to describe and simulate the GAC adsorption equilibrium results.

Table 3 Hybrid Langmuir-Freundlich isotherm constants of GAC adsorption $\left(25^{\circ} \mathrm{C}\right)$

In the GAC adsorption kinetics experiments, DOC in four different wastewaters were quickly adsorbed within the first 90 minutes and remained consistent after that. In the other words, during the first 90 minutes, the available sites in the coal based GAC surface for adsorption were abundant. When all the adsorption sites were occupied and the rates of adsorption and desorption were balanced, DOC removals by adsorption were constant. 
The study of adsorption kinetics is extremely relevant to the design of an adsorption system because it yields the necessary data to estimate the mass transfer from the bulk solution to adsorbent surface and to the interior of the adsorbent particle. In the kinetics adsorption study, LDFA model was employed to describe and predict particle diffusion mechanism and organics removal by GAC. As can be seen from Figure 1, the GAC adsorption can be successfully predicted by LDFA - hybrid isotherm model. The film mass transfer coefficient $\left(\mathrm{k}_{\mathrm{f}}\right)$ was found to be higher in case of synthetic wastewater than that of real wastewater. For example, $\mathrm{k}_{\mathrm{f}}$ (synthetic PTSE) was $2.1 \times 10^{6}$ compared to $\mathrm{k}_{\mathrm{f}}$ of $2.1 \times 10^{5}$ (real PTSE) while $\mathrm{k}_{\mathrm{f}}$ of $5.2 \times 10^{5}$ (synthetic BSTE) compared to $3.1 \mathrm{x}$ $10^{4}$ (real BSTE).

Figure 1 GAC adsorption kinetics with LDFA + hybrid isotherm model ((a) synthetic BTSE; (b) synthetic PTSE; (c) real BTSE; (d) real sewage)

\subsection{Performance of BGAC bioadsorption}

\subsubsection{Biomass growth on GAC}

The results showed that the biomass attached onto the GAC reached the steady phase after 15 days with an amount of approximately $3 \mathrm{~g} / \mathrm{L}$. During the acclimatization, the 5 $\mathrm{ml}$ of GAC was taken from tank at different period of time to measure the specific oxygen uptake rate (SOUR), indicating the microbial activity of the biomass on GAC.

The SOUR results indicated that the microbial activity was stronger after $5^{\text {th }}$ day which corresponds to the higher dissolved oxygen (DO) consumption value. SOURs were achieved to $37.7 \%$ and $34.7 \%$ within 30 minutes on the $10^{\text {th }}$ day and $15^{\text {th }}$ day, 
respectively (Figure 2).

Figure 2 SOUR of biomass on GAC

\subsubsection{BGAC bioadsorption in DOC removal}

As same as GAC adsorption, the higher dosage BGAC resulted in the higher DOC removal. This is due to the available sites for adsorption and more number of micro-organisms attached onto the GAC for organic biodegradation. The DOC removal efficiency increased from $29 \%$ to $96 \%$ (BGAC from $0.1 \mathrm{~g} / \mathrm{L}$ to $2 \mathrm{~g} / \mathrm{L}$ ) in case of the experiments done with synthetic BTSE. With synthetic PTSE, an amount of 3.5 g/L BGAC could almost remove $100 \%$ DOC while only $21 \%$ DOC removal with BGAC dose of $0.1 \mathrm{~g} / \mathrm{L}$. The BGAC bioadsorption also performed well on DOC removal from real wastewater. Table 4 shows that the DOC removal efficiencies in real BTSE decreased from $96 \%$ to $48 \%$ when BGAC dose reduced from $0.75 \mathrm{~g} / \mathrm{L}$ to $0.1 \mathrm{~g} / \mathrm{L}$. For the BGAC bioadsorption with real PTSE, the optimum dose is $5 \mathrm{~g} / \mathrm{L}$ which resulted in approximately $97 \%$ removal efficiency.

Table 4 Performance of GAC bioadsorption

Compared with GAC adsorption, GAC bioadsorption had significantly better performance (Figure 3). The results indicate that only $2.5 \mathrm{~g} / \mathrm{L}$ of BGAC bioadsorption resulted in as same DOC removals $(84 \%)$ as $50 \mathrm{~g} / \mathrm{L}$ of GAC adsorption from real PTSE. Thus, BGAC, with both adsorption and biodegradation mechanisms in removing organic contaminants from wastewater, has the advantage of lowing the cost and 
prolonging the life of GAC.

Figure 3 Performance comparisons of GAC adsorption and GAC bioadsorption

It was found that BGAC bioadsorption with wastewaters required longer equilibrium time for all the dosages investigated. Dissolved organics were removed from wastewater quickly within the first 6 hours, and then the removal rates increased gradually during the next 66 hours. It can be explained that at beginning the adsorption of GAC was more predominant and after the available sites were occupied, the organic matters were biodegraded by the activity of microorganisms which colonized the external surface and macro-pores of the GAC.

\section{Conclusions}

- DOC could be effectively removed by either GAC adsorption or bioadsorption from different kinds of wastewater;

- BGAC bioadsorption performed significantly better than GAC adsorption,

- BGAC bioadsorption could lower the GAC dose and prolong the life time of GAC,

- Hybrid Langmuir-Freundlich model could successfully describe the GAC adsorption equilibriums with different wastewaters. The adsorption kinetics model with organic matters was also well predicted by LDFA + hybrid isotherm model.

\section{Acknowledgements}


This research was funded by ARC linkage project (LP 0775149). The authors are also grateful to the supports of Sydney Olympic Park Authority (SOPA) and Activated Carbon Technologies Pty Ltd.

\section{References}

Aktas, O., Cecen,F., 2007. Biorefgeneration of activated carbon: A review. International Biodeterioration \& Bioderadation, 59, 257-272.

APHA ,1998. Standard Methods for the Examination of Water and Wastewater, $20^{\text {th }}$ ed. American Public Health Association, Washington, DC.

Bansal, R.C., Goyal, M., 2005. Activated carbon adsrotpion, CRC press, USA

Carvalho, M.F., Duque, A.F., Goncalves, I.C.,Castro, P.M.L., 2007. Adsorption of fluorobenzene onto granular activated carbon: Isotherm and bioavailability studies. Bioresource Technology, 98, 3423-3430.

Cooney, D.O., 1998. Adsorption design for wastewater treatment, Lewis Publisher, New York.

Devi, R., Dahiya, R.P., 2008. COD and BOD removal from domestic wastewater generated in decentralised sectors. Bioresource Technology, 998,344-349.

Gordon M., 1996. Use of Adsorbents for the removal of pollutants from wastewater, CRC press.

Hoa, K.L., Chung, Y.C., Lin, Y.H. and Tseng C.P., 2008. Microbial populations analysis and field application of biofilter for the removal of volatile-sulfur compounds from swine wastewater treatment system. Journal of Hazardous Materials 152(2), 580-588. 
Hoang, T.T.L., 2005. Granular activated carbon (GAC) biofilter in water and wastewater treatment, M.E.thesis, University of Technology, Sydney.

Lee, J.W., Yang, T.H., Shim, W.G., Kwon, T.O., Moon, I.S., 2007. Equilibria and dynamics of liquid-phase trinitrotoluene adsorption on granular activated carbon: Effect of temperature and pH, Journal of Hazardous Materials, 141(1) 185-192.

Lee, S.H., Vigneswaran, S., Moon, H., 1997. Adsorption of phosphorus in saturated slag media columns, Sparation and Purification Technology, 12,109-118.

Loh, K.C. and Ranganath, S., 2005. External-loop fluidized bed airlift bioreactor (EFBAB) for the cometabolic biotransformation of 4-chlorophenol (4-cp) in the presence of phenol. Chemical Engineering Science, 60, 6313-6319.

Maloney, S.M., Adrian, N.R., Hickey, R.F. and Heine, L., 2002. Anaerobic treatment of pinkwater in a fluidized bed reactor containing GAC. Journal of Hazardous Materials, $92,77-88$.

Nishijima, W., Akama, T., Shoto, E. and Okada, M., 1997. Effect of adsorbed substances on bioactivity of attached bacteria on granular activated carbon. Water Science and Technology, 35(8), 203-208.

Persson, F., Ngnark, J.L., Heinike, G., Hedberg, T., Tobiason, J., Stenstro, T.A. and Hermansson, M.., 2005. Characterisation of the behaviour of particles in biofilters for pre-treatment of drinking water. Water Research, 39, 3791-3800.

Passos, C.G., Lima, E.C., Arenas, L.T., Simon, N.M., Cunha, B.M., Brasil, J.L., Costa, T.M.H., Benvenutti, E.V., 2008. Use of 7-amine-4 azahepthylsilica and 10-amine-4 
azadecylsilica xerogels as adsrorbent for $\mathrm{Pb}(\mathrm{II})$ kinetics and equilibrium study. Colloids and Surfaces A: Physicochem.Eng.Aspect, 316 (1-3), 297-306.

Zhao X., Hickey, R. F. and Voice,T.C., 1999. Long-term evaluation of adsorption capacity in a biological activated carbon fluidized bed reactor system. Water Science and Technology, 33(13), 2983-2991. 
Table 1 Composition of synthetic BTSE and PTSE

\begin{tabular}{|c|c|c|}
\hline \multirow{2}{*}{ Compound } & \multicolumn{2}{|c|}{ Concentration (mg/L) } \\
\hline & BTSE & PTSE \\
\hline Glucose & - & 230 \\
\hline $\mathrm{NH}_{4} \mathrm{HCO}_{3}$ & 19.8 & - \\
\hline$\left(\mathrm{NH}_{4}\right)_{2} \mathrm{SO}_{4}$ & 7.1 & 71 \\
\hline $\mathrm{K}_{2} \mathrm{HPO}_{4}$ & 7 & - \\
\hline $\mathrm{KH}_{2} \mathrm{PO}_{4}$ & - & 13.2 \\
\hline Peptone & 2.7 & 2.7 \\
\hline Humic acid & 4.2 & 4.2 \\
\hline Tannic acid & 4.2 & 4.2 \\
\hline (Sodium) lignin sulfonate & 2.4 & 2.4 \\
\hline Sodium lauryle sulphate & 0.94 & 0.94 \\
\hline Acacia gum powder & 4.7 & 4.7 \\
\hline Arabic acid (polysaccharide) & 5 & 5 \\
\hline \multicolumn{3}{|l|}{ Trace nutrient } \\
\hline $\mathrm{MgSO}_{4} \cdot 7 \mathrm{H}_{2} \mathrm{O}$ & 0.71 & 5.07 \\
\hline $\mathrm{CaCl}_{2} \cdot 2 \mathrm{H}_{2} \mathrm{O}$ & 0.0184 & 0.368 \\
\hline $\mathrm{MnCl}_{2} \cdot 4 \mathrm{H} 2 \mathrm{O}$ & 0.01375 & 0.275 \\
\hline $\mathrm{ZnSO}_{4} \cdot 7 \mathrm{H}_{2} \mathrm{O}$ & 0.022 & 0.44 \\
\hline $\mathrm{FeCl}_{3}$ & 0.0725 & 1.45 \\
\hline $\mathrm{CuSO}_{4} .5 \mathrm{H}_{2} \mathrm{O}$ & 0.01995 & 0.391 \\
\hline $\mathrm{CoCl}_{2} \cdot 6 \mathrm{H}_{2} \mathrm{O}$ & 0.021 & 0.42 \\
\hline $\mathrm{Na}_{2} \mathrm{MoO}_{4} \cdot 2 \mathrm{H}_{2} \mathrm{O}$ & 0.063 & 1.26 \\
\hline Beef extract & 1.8 & - \\
\hline Yeast extract & - & 20 \\
\hline
\end{tabular}


Table 2 Performance of GAC adsorption

\begin{tabular}{cccc}
\hline Wastewater Type & $\begin{array}{c}\text { Dose } \\
(\mathrm{g} / \mathrm{L})\end{array}$ & $\mathrm{q}(\mathrm{mg} / \mathrm{g})$ & $\begin{array}{c}\text { DOC removal } \\
\text { efficiency }(\%)\end{array}$ \\
\hline & 0.25 & 13.88 & 40.63 \\
Synthetic BTSE & 0.5 & 8.52 & 49.88 \\
& 1 & 5.10 & 59.72 \\
& 2.5 & 2.47 & 72.25 \\
Synthetic PTSE & 5 & 1.58 & 92.85 \\
\hline & 2.5 & 9.82 & 21.67 \\
& 5 & 7.26 & 32.05 \\
& 25 & 5.37 & 47.40 \\
Real BTSE & 50 & 3.21 & 70.80 \\
& 0.1 & 4.89 & 83.57 \\
\hline & 0.25 & 25.84 & 50.78 \\
& 0.5 & 16.52 & 71.62 \\
& 0.75 & 11.60 & 91.60 \\
Real PTSE & 1 & 9.02 & 96.46 \\
& 2.5 & 10.12 & 48.65 \\
\hline & 5 & 5.60 & 53.85 \\
& 10 & 3.16 & 60.75 \\
& 25 & 1.51 & 72.40 \\
& 40 & 1.07 & 82.16 \\
\hline
\end{tabular}


Table 3 Hybrid Langmuir -Freundlich isotherm constants $\left(25^{\circ} \mathrm{C}\right)$

\begin{tabular}{clcccc}
\hline & & Synthetic BTSE & Synthetic PTSE & Real BTSE & Real PTSE \\
\hline & $\mathrm{q}_{\mathrm{m}}$ & 1.472 & 9.06 & 1.25 & $2.96 \mathrm{E}-03$ \\
GAC & $\mathrm{b}$ & $4.884 \mathrm{E}+05$ & $1.60 \mathrm{E}-02$ & $2.37 \mathrm{E}+08$ & $1.22 \mathrm{E}-06$ \\
adsorption & $\mathrm{k}$ & $5.492 \mathrm{E}-02$ & $2.77 \mathrm{E}-11$ & 3.21 & $8.43 \mathrm{E}-05$ \\
& $\mathrm{n}$ & $2.97 \mathrm{E}-01$ & $1.72 \mathrm{E}-01$ & $6.39 \mathrm{E}-01$ & $2.80 \mathrm{E}-01$ \\
& $\mathrm{R}^{2}$ & 0.975 & 0.988 & 0.912 & 0.963 \\
\hline
\end{tabular}


Table 4 Performance of GAC bioadsorption

\begin{tabular}{cccc}
\hline Wastewater Type & $\begin{array}{c}\text { Dose } \\
(\mathrm{g} / \mathrm{L})\end{array}$ & $\mathrm{q}(\mathrm{mg} / \mathrm{g})$ & $\begin{array}{c}\text { DOC removal efficiency } \\
(\%)\end{array}$ \\
\hline \multirow{3}{*}{ Synthetic BTSE } & 0.1 & 16.1 & 28.75 \\
& 0.25 & 9.8 & 43.75 \\
& 0.5 & 7.12 & 63.57 \\
& 1 & 4.24 & 75.71 \\
Synthetic PTSE & 0.1 & 2.69 & 96.2 \\
\hline & 0.5 & 27.2 & 21.43 \\
& 1 & 15.12 & 59.57 \\
Real BTSE & 2 & 5.89 & 79.43 \\
& 0.05 & 4.11 & 92.78 \\
& 0.1 & 46 & 97.19 \\
\hline & 0.5 & 33.6 & 32.58 \\
& 0.75 & 12.57 & 47.59 \\
Real PTSE & 9.16 & 73.09 \\
& 1 & 19.58 & 89.01 \\
& 2 & 13.73 & 97.35 \\
\hline & 3.27 & 47.92 \\
& 5 & 6.05 & 67.21 \\
& 3.92 & 80.91 \\
& & & 88.84 \\
& & 95.89 \\
\hline
\end{tabular}




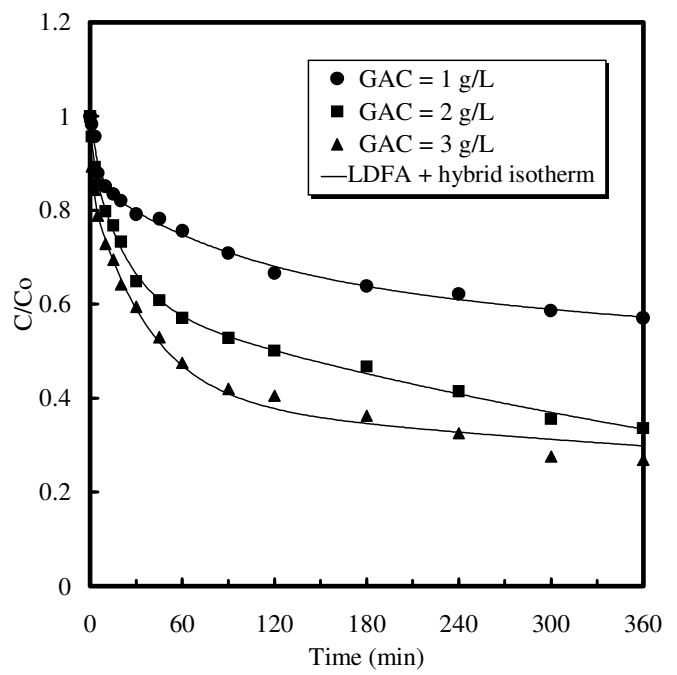

(a)

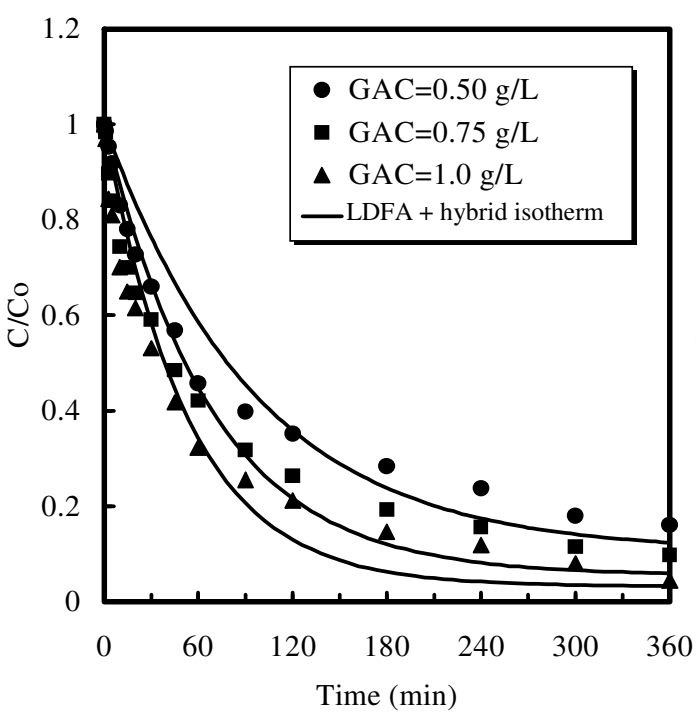

(c)

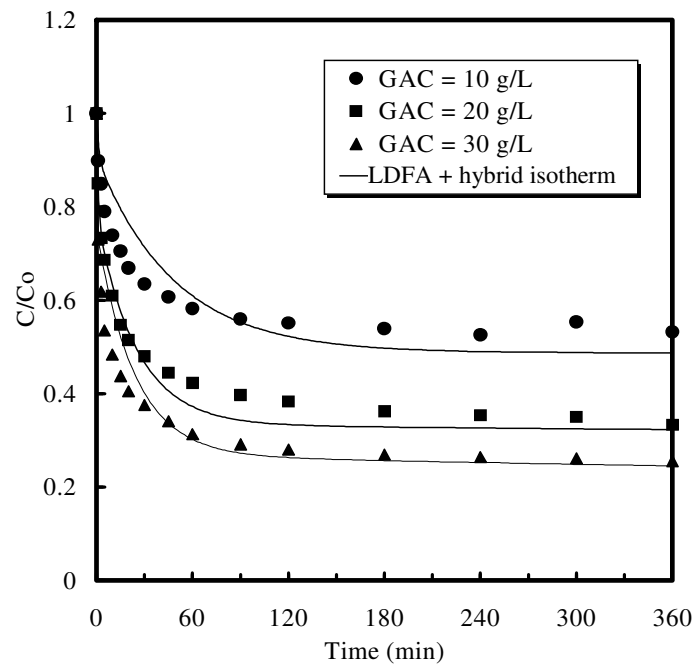

(b)

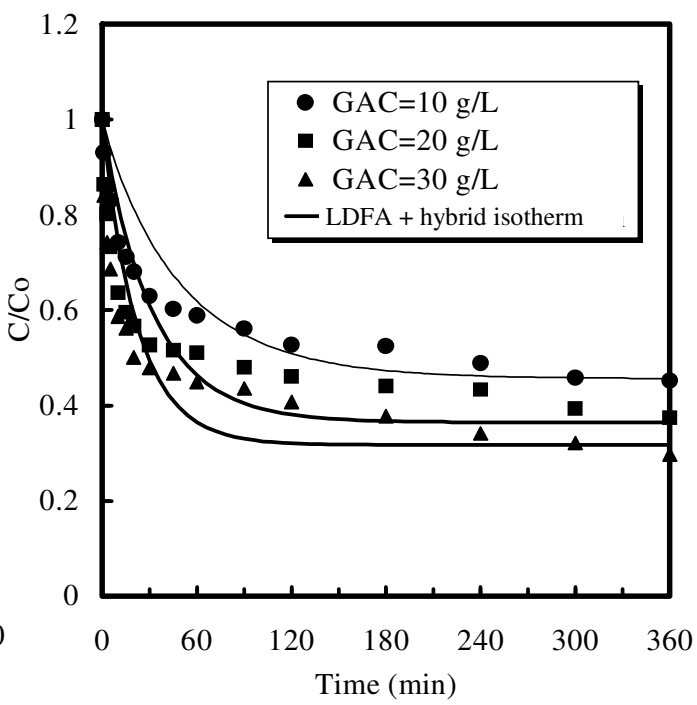

(d)

Figure 1 GAC adsorption kinetics with LDFA + hybrid isotherm model ((a) synthetic BTSE; (b) synthetic PTSE; (c) real BTSE; (d) real sewage) 


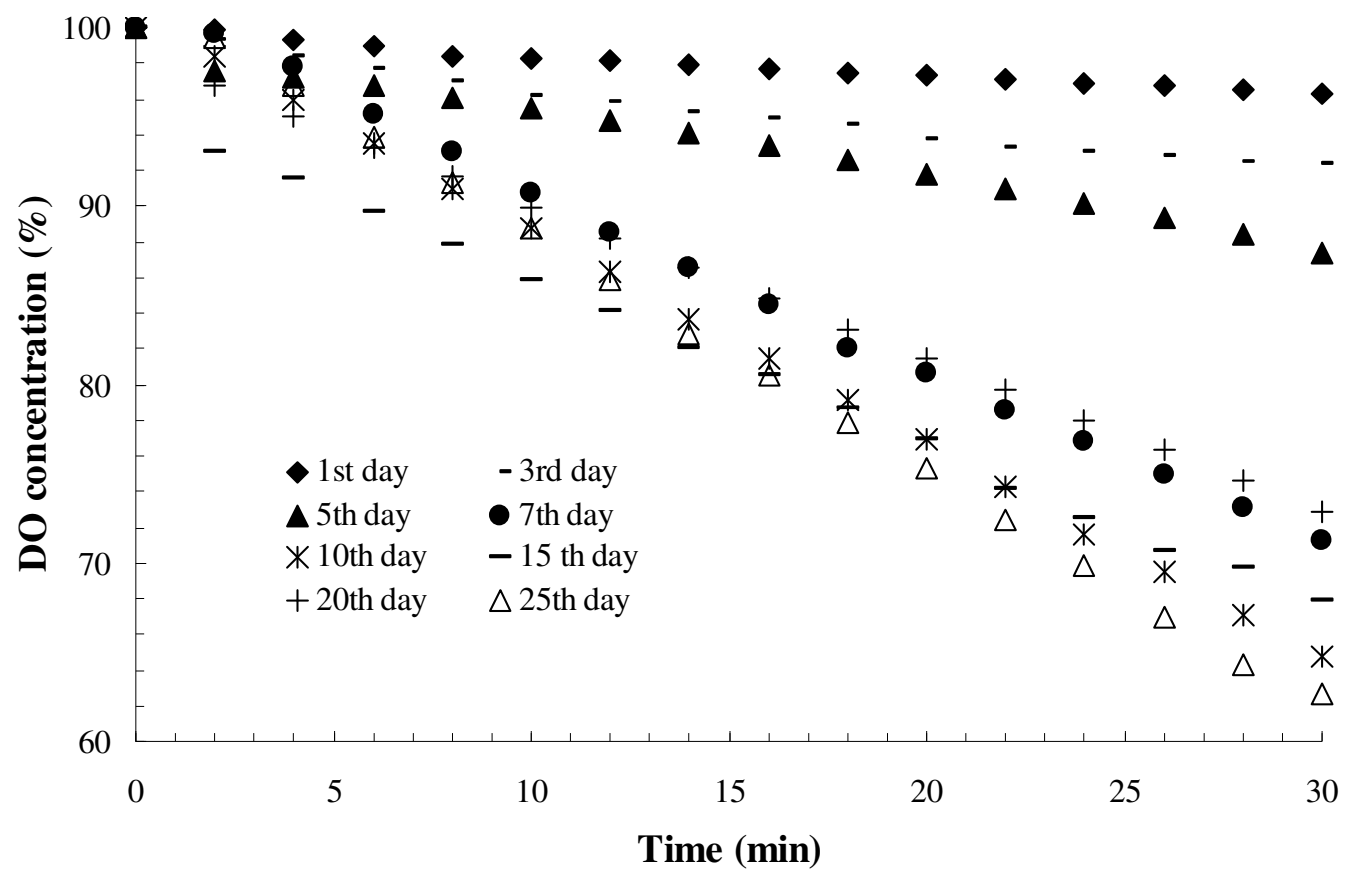

Figure 2 SOUR of biomass on GAC 


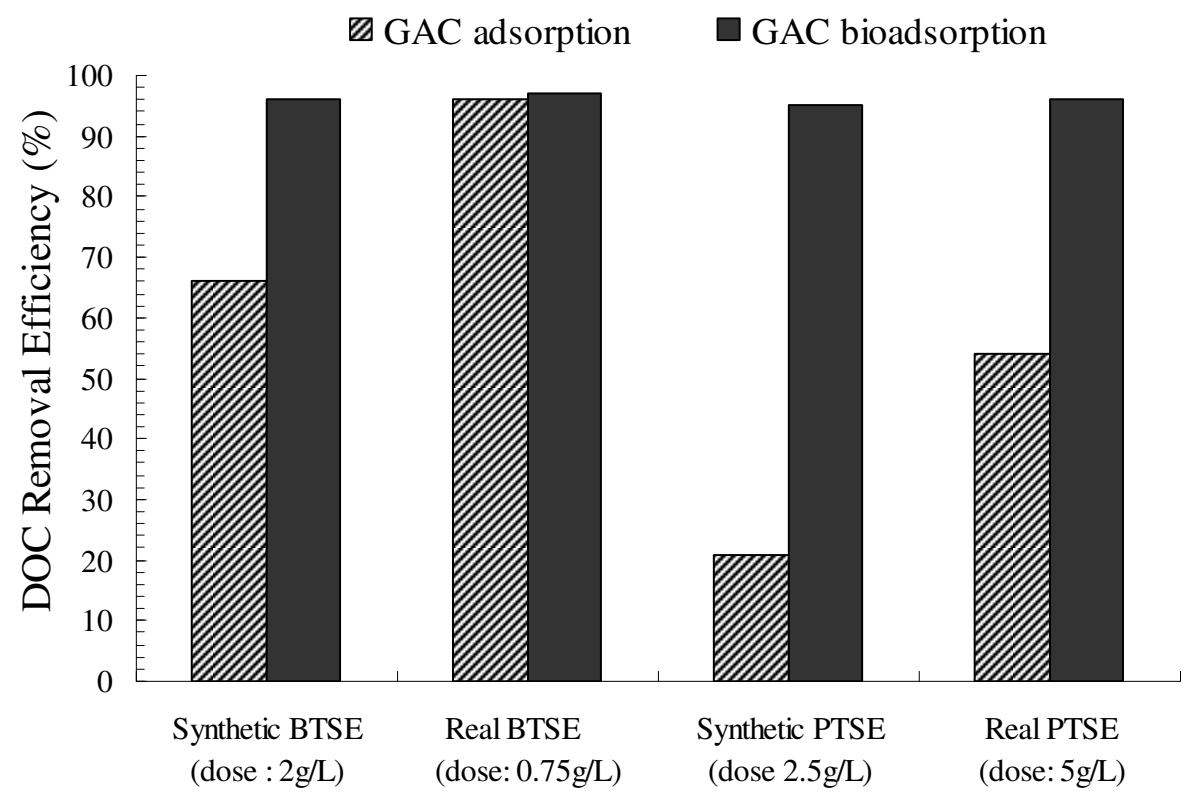

Figure 3 Performance comparisons of GAC adsorption and GAC bioadsorption 